\title{
"MAY THE FORCE MOVE YOU": \\ ROLES AND ACTORS OF INFORMATION SHARING DEVICES IN URBAN MOBILITY
}

\author{
Giovanni Vecchio $^{\text {a, b, }}$, Luca Tricarico ${ }^{d}$ \\ a Department of Transport Engineering and Logistics, Pontificia Universidad Católica de Chile, \\ Chile \\ ${ }^{\mathrm{b}}$ Centre for Sustainable Urban Development (CEDEUS), Chile \\ ${ }^{c}$ Department of Architecture and Urban Studies, Politecnico di Milano, Milan, Italy \\ ${ }^{\mathrm{d}}$ Nesta Italia, Turin, Italy
}

Corresponding author at: Department of Transport Engineering and Logistics, Vicuña Mackenna 4860, Macul, Santiago, Chile. giovanni.vecchio@uc.cl

Through the Force, things you will see.

Yoda, in The empire strikes back

\section{Introduction: Information, an invisible and yet powerful force behind urban mobility}

Mobility plays a significant role in the socio-economic dynamics of cities and in individuals' everyday lives. Mobility is nowadays transforming societies, and is both a fundamental phenomenon to understand them, both a crucial requisite to participate in social life (Canzler, Kaufmann, \& Kesselring, 2008; Cresswell, 2010; Kaufmann, 2002; Sheller \& Urry, 2006, 2016; Urry, 2007). While societies are increasingly mobile and interconnected, new ICT tools are becoming more and more relevant for moving, accomplishing tasks and creating relationships, even at considerable distances (Elliott \& Urry, 2010). The innovation recently brought into the market for mobility by apps, social networks and sharing economy initiatives not only impacts 
upon the economic appeal of urban areas, but also affects people's mobility choices and preferences, modifying any aspect related to different forms of 'urban consumption' (van Wee, Geurs, \& Chorus, 2013). One significant contribution is provided by those mobile devices that contribute to sharing information, defined in this case as the facts provided or learned about mobility in a given setting. Several 'sharing devices' are nowadays producing such effects: these include platforms where mobility information is stored and exchanged, diverse devices that promote efficient choices by nudging people towards complex mobility behaviours, unprecedented modal options supported by new forms of mobility supply made available by technologies (Evans \& Schmalensee, 2016). In a sense, information and the devices that share it represent an invisible and yet powerful force behind contemporary urban mobility trends.

This paper discusses the role of information-sharing devices in shaping individuals' mobility choices. We do so by referring to a wide range of innovations recently implemented in the mobility market, which provide varied information, satisfy variegated preferences, promote market efficiency and take advantage the human capital concentration of urban contexts. These technologies in fact may convey useful tools to the whole community of users, promoting more symmetric information in the mobility market and even supporting alternative ways for providing services. The innovation lies in the way in which information-related technologies influence people's mobility choices (van Wee et al., 2013): such impact is achieved for example by intercepting personal motivations (like the reduction of travel expenses), by providing new stimuli (as forms of gamification do) or by raising new attitudes (for example, more sustainable behaviours). As discussed further, these initiatives may be considered innovative also because these are often developed outside the traditional schemes of public policy or big private investments. 
Information-sharing devices can facilitate the use of existing mobility services and the recourse of new alternative solutions, since they may provide previously unavailable information or make it more easily understandable (Tricarico, Vecchio, \& Testoni, 2016). Moreover, by favouring the availability of a wider set of mobility options, such devices may improve individual access to urban opportunities. However, urban and transport planning still pay little attention to the relevance that also information may have for citizens wellbeing, so that an exploration of such widespread technologies and the unprecedented spatial practices they foster may be relevant. Despite a general phenomenological interest in new mobility practices (Knoben et al., 2008; Priemus, Nijkamp, \& Banister, 2001), urban and transport planning schools are still overlooking in-depth theoretical and empirical investigation and experimentation of any specific driver of innovation - including information. Similarly, also planning approaches have not yet exploited the potential of information for understanding individual mobility choices and orientating them towards better, smarter, and more sustainable travel behaviours.

Drawing on a literature review referred to a wide set of new technologies and shared mobility practices based on significant information related to mobility, the paper draws its discussion on three analytical dimensions: first, the role that information has in shaping individual mobility choices, and how it may interact with individual preferences and needs (section 2); second, the varied forms of relevant mobility information made available by information-sharing devices (section 3); third, the many actors (corporations, public administrations, community groups...) who produce information collecting data and making them available in different forms (section 4). Drawing on these three elements, a policy framework for defining suitable operational approaches is discussed in section 5. The paper grounds its reflection in the fields of human geography and urban policy analysis combined with behavioural economics, focusing on how information influences individual decisions and support the satisfaction of mobility preferences. By discussing the relevance of information and its manifold features (in terms of sources, objects and forms), the 
paper can contribute to urban mobility policies that are more attentive to individual preferences and more effective in terms of sustainability. In fact, the discussed issue allows to better understand how information impacts individual mobility choices, focusing on one of the crucial features that define mobility demands. On the other hand, the paper highlights useful elements to nudge individual mobility choices towards practices with wider collective benefits, for example promoting the use of more sustainable mobility alternatives.

\section{The role of information in shaping choices}

Information is increasingly recognised as a key influence on individuals' mobility choices, as part of a 'behavioural turn' in transport policy (Barr and Prillwitz, 2014; te Brömmelstroet, 2014) that also influences operational approaches to relevant mobility issues. While each setting provides a specific set of mobility infrastructures and services, the appropriation of such provision depends on an individual decision made by each subject. According to one's aims, resources and attitudes, each person has a different potential to be mobile, which may be transformed or not into travel (Kaufmann, 2002). Information contributes to the individual mobility skills, generically definable as "an actor's savoir-faire" (Flamm \& Kaufmann, 2006, p. 169), by contributing to the knowledge that a person acquires in relation to mobility - that is, the sum of what is known in relation to it; to gain information people also need an "organisational capacity in order to plan activities (researching information, ability to adapt to short-term changes, etc.)" (ibidem). To allow individual mobility, the availability of information and communication technologies is as relevant as the means for physical movement: they are similarly constitutive of mobility as well as of new social forms, according to which "cars, information, communications, screens, are all material worlds, hybrids of private and public life" (Sheller \& Urry, 2003, p. 122). Interestingly, in some cases it is ICT that make a transport mean available. For example, this is the case for 'smart' 
mobility initiatives involving electromobility, shared use mobility, and mobility as a service, in which ICT make possible the access to such means (Nikitas et al., 2017).

Behavioural economics and psychology provide insights into the way in which information becomes knowledge and therefore influences mobility behaviours. Their focus is on 'choice architecture': it is the ensemble of environmental elements that affects the way people access and use information and thereby influence their decisions (Kahneman, 2011; Thaler \& Sunstein, 2008; Simon, 1955). Changes to the choice architecture provide opportunities to intervene on individual behaviour, in order to "move people in directions that will make their lives better" (Thaler \& Sunstein, 2008, p. 6). These sorts of intervention are now known as nudges. Also travel-related strategies could then be examined "not only by the amounts of travel that individuals actually did, but also by their subjective assessments, desires, and affinities with respect to travel" (Cao \& Mokhtarian, 2005, p. 300). Behavioural elements are crucial to recognize the mechanisms that influence choices (Anable, 2005; Cairns et al., 2008; Cao \& Mokhtarian, 2005; Kazhamiakin et al., 2015) and, since individual choices are the basic units that compose practices, these also allow to define different mobility profiles (Schwanen, 2015).

The influence of information on decisions concerning individual mobility may be heterogeneous. Depending on their preferences, individuals having different preferences give different weights to diverse informational dimensions. For example, Cao and Mokhtarian (2005) discuss how subjects travelling for short distances privilege strategies that reduce the costs of the trip, given that other factors (such as the distance to be covered and the frequency of the trip) are difficult to be addressed. Hence, policy approaches interested in promoting better mobility practices may take advantage of information by providing those elements that, depending on the heterogeneity of individual preferences, are able to suggest mobility choices more aligned with individual preferences. Mobility policy approaches in fact could promote more efficient and sustainable 
practices by fostering alternative behaviours (te Brömmelstroet, 2014), but orderly approaches are required to detect individual preferences and consequently provide relevant information.

Strategies based on mobility-related information can intercept also the individual sphere of aspirations, perceptions and feelings. Manifold are the contributions of information in this sense. First, information can promote a higher awareness of benefits and costs associated to specific modal choices, depending on individual attitudes: for example, if data related to the pollutant emissions of different modal options are made visible, a person sensitive to environmental issues may decide to adopt different travel behaviours (Anable, 2005). Also the monetary and temporal costs associated to different mobility alternatives can become visible and comparable, allowing comparisons that may inspire different, 'smarter' individual travel choices (Cairns et al., 2008). On the contrary, information can highlight more profitable choices, for example when rewards are offered: this is the case of the Dutch Spitsmijden experiment, in which road congestion was tackled scheduling the trip of commuters and introducing a reward for shifting departure times (Knockaert et al., 2012). Also, information can increase pleasure in services user experiences, for example using gamification mechanisms: this is the case for initiatives that, within a limited time frame, use apps to record users' travel behaviours, provide comparisons between different travel alternatives, give points to those who switch toward more sustainable modal choices, and finally reward those with the higher scores; an experimentation of this mechanism was successfully led for example in Rovereto, Italy (Kazhamiakin et al., 2015). The targets achievable with information-based interventions include a wide range of "important goals of the transport systems (such modal change, higher safety, CO2 reductions, higher level of service)" (te Brömmelstroet, 2014, p. 141). Behavioural approaches may thus promote alternative behaviours also by creating occasions for new choices, assuming different aims according to the examined settings 


\section{Varied forms of information}

Manifold are the forms of information that contribute to the shaping of urban mobility behaviour. The spreading of information-sharing devices widens the range of facts provided or learned about mobility in a given setting, which each person can master. These may refer to the features of the available mobility opportunities as well as to the way in which users perceive them, consequently influencing individual mobility choices. It is significant to distinguish between different kinds of notions related to mobility, which we may define as objective and subjective information.

- Objective information refers to the characteristics of the available mobility opportunities, conveying the overall framework within which individual displacements between one place and another are possible. Objective information may regard fixed or variable elements.

- Fixed elements are those defining the opportunities for movement differently available in each context (Ryan, Wretstrand, \& Schmidt, 2015). Three dimensions can be recognised: the spatial dimension, involving infrastructures and services available between the origin and the desired destination; the temporal dimension, including timetables and service hours; the monetary dimension, referred to the costs of each travel alternative. Fixed, objective information is traditionally provided with analogic tools such as maps, leaflets and boards; information-sharing devices facilitate real-time access to such information and the comparison of alternative options, even when referring to different modal options (the core mission of apps such as Wanderio, GoEuro, fromAtoB).

- Variable elements encompass objective information about the alternative mobility choices available. Variable information refers to temporary conditions of mobility services and infrastructures, including elements that affect the possibility to make 
use of them. They convey real-time, updated information concerning, for example, the state of service of an infrastructure, signalling congested streets and suggesting alternative routes; the regularity of a given service, displaying waiting times and eventual delays; the availability of a specific modal option, showing the available shared vehicles in nearby areas; even changing monetary costs, associated for example with dynamic price systems. Variable objective information is provided through physical devices with variable message signs, and by apps available in portable devices (i.e. smartphones). The relevance of such information is twofold. On the one hand, it could orientate decisions before the beginning of a trip; an example are the apps offered by municipal transport utilities, which inform of service irregularities due to which a given alternative is not available due to delays ${ }^{1}$. On the other hand, it could change ongoing practices, directing them towards more efficient choices (as in the case of the alternative road routes shown in real time by routing apps like Google Maps or Waze).

- Subjective information refers instead to how mobility opportunities are experienced by their users. This is probably the information typology that benefits more from the spreading of information-sharing devices, which allows the collection of information produced by individuals and their aggregation. Here we do not refer to big data tracking for example mobility flows, but rather the information that is voluntarily and qualitatively provided by the users of specific modal options. For example, it is the case of the rating mechanisms involving car sharing and ride sharing systems: users of Uber, Lyft and the likes are invited to evaluate their trips, offering an indication of the service quality that can benefit both the

\footnotetext{
${ }^{1}$ For instance, Rome municipality have launched both WhatsApp and Twitter accounts for live information service (http://www.atac.roma.it/page.asp?p=56 )
} 
providers, both the future users of the same service (even if various are the critical features associated to such reputation mechanisms). Even the individual perceptions and preferences associated to specific trips and routes can be gathered, allowing different modal choices according to individual preferred options; this is the case of apps related to cycling routes (e.g. CycleStreets in the United Kingdom, BikeDistrict in the city of Milan), which allow to choose different paths if the user values more the speed or the safety of the trip. These aspects work on the present perception of the currently available modal options, even if also perceptions of oneself (Macfarlane, Garrow, \& Mokhtarian, 2015) and past experiences (Smart \& Klein, 2017) have a strong influence in this sense.

Both objective and subjective information, as made available by information-sharing devices, may influence mobility behaviour. They do so by increasing the individual access to relevant notions concerning varied modal options. This could concern information previously not accessible or shareable, as in the case of real-time conditions of mobility services and infrastructures; or it could simply refer to notions that are made more easily accessible and understandable, for example thanks to tailored queries that only show to the user the specific travel option she requires instead of showing the entire service network available. However, the simple availability of information is not sufficient to influence individual mobility preferences, since people may be differently able to access and process information. First, people may not have the possibility to own or use information-sharing devices or may lack the abilities required to make use of them, highlighting the existence of a digital divide (Graham, 2011). Second, the very ability to process information, understanding its contents and putting it into use, may change according to different cognitive and literacy skills. The ability to make use of information is a dynamic skill, which could be acquired, adapted or lost over one's life (Banister \& Bowling, 2004; Goodman et al., 2014; Stjernborg, Wretstrand, \& Tesfahuney, 2014), and the loss of such ability is a problem especially for ageing populations (Nordbakke, 2013; Ryan et al., 2015). A partial response in this sense are the 
employment of universal design in apps and the development of devoted apps for people with disabilities (Gebresselassie \& Sanchez, 2018).

\section{The shapers of information}

The spreading of information technology allows the involvement of a large set of actors in the production of information and its consequent processing into usable forms. The presence of traditional and emerging subjects enriches and at the same time complicates the provision of relevant mobility-related information. The considerable amount of available data requires interpretative skills to individuate and process significant information, and the interactions between the scattered subjects to which such data are available are a further element of attention. Traditional actors, such as public administrations and public transport service providers, have a primary role in the production and the provision of information; nonetheless, the ongoing decrease of publicly available resources leads to a reduction of public infrastructural investments (OECD, 2015) and diminishes the institutional contribution to mobility-related innovations. We choose thus to focus on those emerging actors who produce information and make it usable in innovative ways, examining the role of corporations and communities.

\subsection{Corporations}

We may consider corporations as the most active subjects in the development of new technologies for the everyday mobility of people and goods, due to their role both in the experimentation of new vehicles (such as drones, self-driving cars, electric vehicles, automated public transport systems) and the unprecedented forms of service provision that rely on new information sources. Sharing economy enterprises are probably the most interesting case in relation to information, since these initiatives are based on the collection and the use of mobility-related data: these work 
with the sharing of rides (e.g. Uber, BlaBlaCar, Heetch), cars (e.g. Car2Go, Zipcar), bicycles (e.g. JCDecaux, Motivate, Ofo, Mobike), even with innovative vehiles such as electric motorbikes and scooters (as the company Mimoto does in Milan and Bird in Los Angeles). The ridesharing companies provide a relevant example in this sense. To run their service, these companies gather data from various sources: the geo-localisation of users and drivers, as provided by their mobile devices; the local road infrastructure and its conditions of use, portrayed by traffic and navigation apps like Google Maps and Waze; the real-time features influencing the availability of the service and its cost (e.g. demand intensity, meteorological conditions), collected with the latter mentioned sources. The operations of Uber are based on the analysis of these diverse sources, facilitated by the fact that the company mainly offers its service within the municipal boundaries of the main world metropolises. Relevant is also the subsequent use of these data. On the one hand, Uber has launched a service - Uber Movement - that provides access to the aggregated data collected by the service, intending it as a tool to "inform decisions about how to adapt existing infrastructure and invest in future solutions to make our cities more efficient" (Uber, 2017). On the other hand, the company also sells the collected information, getting consistent revenues that rather configure Uber as a big data company (Hirson, 2015).

Information is a product of and a condition of access to the services offered by corporations. It is a paradox, which Morozov (2016) deeply discusses: thanks to data, big technological companies provide services so pervasive that they are almost a 'default background' of contemporary societies. In a moment of growing delegitimization for contemporary democracy, technological companies "have already taken on the de facto responsibilities of the state; any close analysis of what's happening with 'smart cities' - whereby technology firms become key gateways to essential services of our cities - easily confirms that". Technological firms are testing new initiatives in urban settings by experimenting unprecedented typologies of vehicles and services, opening new scenarios for the development of cities and societies. Nonetheless, innovative 
initiatives are not exclusively in charge of big companies: the spreading of technologies is fostering new experimentations from below, as the next subsection explains.

\subsection{Community groups}

Community groups (organized and/or informal) and networks may give life to associative or entrepreneurial initiatives originated from groups involved in specific activities or due to conditions of proximity (geographical, cognitive etc.; see Boschma, 2005). Virtual and non-virtual community groups can raise initiatives based on a bottom-up approaches in sharing and aggregating information and preferences (van Ham et. al, 2017; Tricarico, 2017). The strength of these initiatives derives from the voluntary engagement of people who have interests, needs or final destinations in common. Recognizing the existence of common issues or opportunities, these groups can better face them not only sharing economic resources, but also valorising information produced by the active participation of individuals in a common space of dialogue and contextual knowledge. In and outside the field of mobility, community groups have a strong role in expressing specific issues related to their contextual needs, promoting local sustainability and efficient solutions by being vocal about sensitive issues or becoming promoters of bottom-up initiatives (Moroni \& Tricarico, 2017; Vecchio, 2016). These initiatives can thus complement social and technological innovation, going beyond the apparent dichotomy between the two terms (Turkle, 2011).

Community groups provide three specific contributions in relation to information: they mobilise latent resources, transmit them, and facilitate thus encounters of demand and offer:

- Mobilise latent resources. Communities can stimulate initiatives that, despite being small spontaneous projects, are often able to get significant market shares (Tricarico, 2016; Bailey, 2012; Aiken et al. 2011; Tracey et. al, 2005). These initiatives in fact can effectively 
exploit economic and human resources that otherwise would remain latent or unexpressed. Thanks to the direct involvement of interested subjects who act as 'sensors' (Goodchild, 2007), communities gather data concerning the mobility experiences of their users/components, drawing on which they transmit information to the community itself. Among the numerous practices related to this perspective, open source cartographic projects deserve to be mentioned due to their role in updating static maps, providing contextual information based on the specific knowledge that the community has and considers as important for itself. Within the Open Street Map initiative, a collaborative online mapping project, information on public transport is obtained also through the participatory generation of standardized data (Jacquin, 2018). The same approach has proved effective in informal settings, as in Nairobi: the first map of the matatus, the informal bus services of the city, was realised by the project Digital Matatus, which involved students, commuters and frequent users in the generation of data that previously were not available; in the same city, the initiative Map Kibera relied on different digital devices to allow the local marginalised communities to map the informal settlements they live in, which previously had no cartographic representation.

- Transmit useful information. Community initiatives can gather fragmented mobility demands, reflecting manifold exigencies that may not benefit every subject. Drawing on this, innovative services - such as those provided by apps like CityMapper or Nextdoor are able to provide different suggestions for different mobility needs: for example, the same destination could be reached with different routes if the fastest, the cheapest or the healthiest routes are chosen. The quantity and the quality of the available information is crucial to satisfy such different individual mobility needs. The studies in behavioural economics in fact highlight how individuals often make 'wrong' decisions (i.e. decisions that do not reflect their preferences) just because their attention is not focused on the 
information they need to take the best decision. Also user experience reviews are useful to gather and spread information (as in the case of gamification; see Kazhamiakin et al., 2015), as well as to evaluate the effectiveness of urban mobility policy (as when promoting sustainable mobility practices; see Schwanen, 2015);

- Facilitate encounters of demand and offer. Thanks to the information available to them, communities favour also encounters between complementary exigencies. Thanks to spreading of decentralized technologies, is growing the number of matchmakers platforms intending to connect groups expressing complementary demands and offers (Evans \& Schmalensee, 2016). A first example in this sense are companies such as RideConnect and Comovee, which offer the possibility to start private ridesharing circuits; using these apps, a person may coordinate the sharing of rides with colleagues and neighbours. These companies provide thus a platform for matchmaking but do not provide themselves a ridesharing system, which needs to be established by a person or a group of them. This aspect marks the main difference with other ridesharing services such as Uber. A second, more ambitious example refers to alternative forms of car sharing. This is the case for the Car Sharing Lending Platform (CSLP), namely community-based decentralized logistics and transport system that relies on blockchain, smart contracts and GPS technologies. One of them is the Gitto Project, which aims to develop a CSLP solution through the decentralization of information and the tokenization of mobility assets, relying on a chain of blocks that manages information and resources of the local platform. This system might be able to offer the possibility of a peer-to-peer contact where both drivers and passengers offer, request and pay for rides in the blockchain. Tokenized car rental ecosystems may pave the way to new community-based rental enterprises, where owners and customers can rent out their automobile and time under the conditions and terms they determine themselves. A possible end result may be a more competitive market in which 
the actual costs and benefits of car rental can be observed, and the information might be controlled through the blockchain technology.

Such initiatives may have collective benefits, which nonetheless risk being unevenly distributed. More efficient initiatives such as ridesharing reduce the number of vehicles travelling only with their driver, tackling issues of congestion and pollution in ways that have attracted different forms of institutional support (for example, providing cheaper road tolls and promoting the creation from below of local ridesharing systems). However, these initiatives may be unequally available to different territories and communities. As underlined by Pasqui (2015, p. 55), the spread of these highly innovative community developments can be strongly dependent on a "high standard of economic performances and urban infrastructures needed to support these new form of production" and eventually "promoting new asymmetries and spatial inequalities".

\section{Information in urban mobility: towards a policy framework}

The complex nature of information in contemporary societies opens new operational directions also for urban mobility planning and policy and requires defining a devoted framework for initiatives addressing individual behaviours. It is crucial to define how institutions public administrations - especially at the urban and metropolitan level - can exploit the potential of information-based initiatives, according to their possible positive impact on urban mobility issues. In this sense, the three analytical dimensions previously discussed provide a useful guidance (synthetised in figure 1). 


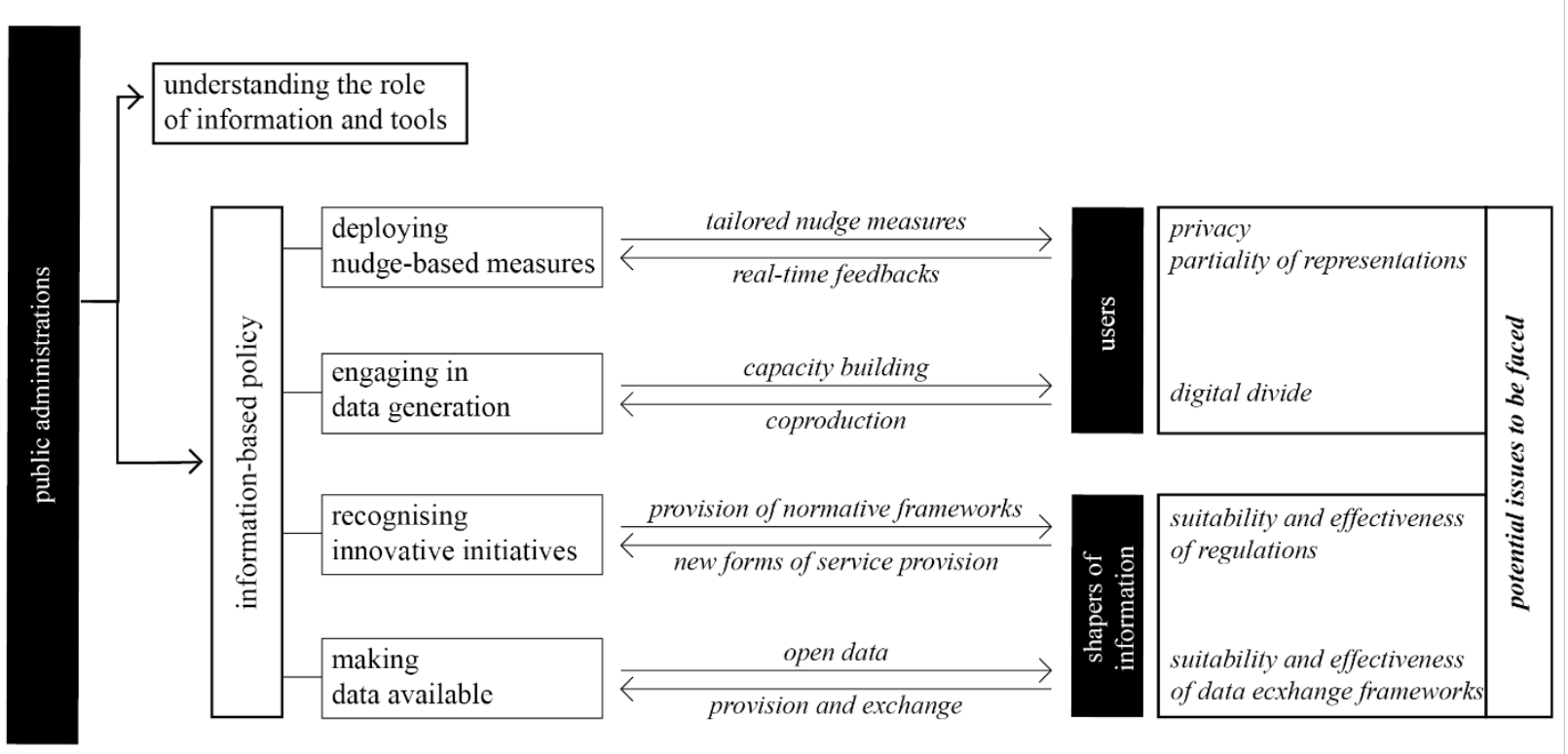

Figure 1. A policy framework for information in urban mobility

\subsection{The role of information}

A focus on information is crucial for a more in-depth knowledge of urban mobility behaviours and paves the way for devoted policy measures. The day-by-day appropriation of mobile media and geolocational data provide in fact unprecedented amounts of information, especially thanks to big data - that is, "everything captured or recorded digitally by modern information and communications technologies such as networked sensors, 'smart' objects and devices, the web and social media" (Rabari \& Storper, 2015, p. 28).

A richer understanding of how information shapes individual mobility preferences and a larger amount of available data allow urban practitioners to address travel choices with more incisive urban mobility policies, attentive to individual needs and effective in terms of sustainability. In fact, the knowledge of urban mobility behaviours provides useful elements to nudge individual mobility choices towards practices with wider collective benefits, for example promoting the use 
of more sustainable mobility alternatives. In this perspective, new technological tools are not fundamental; rather, it is important to understand the functioning of existing ones, gathering relevant information to improve their performances and help define those issues for which the recourse to information-based initiatives is most significant.

However, a wide use of information for analytical purposes raises significant issues of privacy and effectiveness. First, subjects who are producers and recipients of information can be easily tracked and end up having 'no place to hide' (Taylor, 2016): big data in fact are ubiquitous and highly detailed, so that even anonymising data it is easily possible to profile and control citizens. Furthermore, even portable digital devices provide a partial knowledge of everyday urban mobility: algorithms offer partial representations of urban phenomena that are prone to omissions and exclusions (Kwan, 2016), and human mobility is only partially predictable even when having huge and detailed sets of data (Song, Qu, Blumm, \& Barabási, 2010).

\subsection{The forms of information}

Policy measures for urban mobility can rely on information in at least two senses: providing new information to individuals working on their preferences, and defining new forms of service provision thanks to the unprecedented availability of information.

Preferences are central to define how individuals use mobility goods and services to satisfy their individual needs. Individual choices in fact may not be in line with individual preferences, so that incentives towards better decisions could be relevant. This is the core element of the nudge approach (Thaler \& Sunstein, 2008): a concept developed in behavioural economics, the nudge

refers to individual decisional processes and aims at influencing them, by working on the information highlighted in the moment of the choice. The aim is to lead individuals towards decisions that benefit them, even if the individual freedom of choice is not questioned (John et al., 2009). For example, an initiative intending to promote the usage of alternative modal options 
instead of private vehicles may usefully rely on varied forms of information, making them visible in unprecedented ways: real-time comparisons between different mobility alternatives may be based on the cost of a trip or its environmental footprint (objective, fixed information); on the temporal costs of travel, especially in the case of accidents and congestion (objective, variable information); or on the possibility to take alternative, more pleasant routes, for example cycling in a park instead of a trafficked road (subjective information).

A focus on how digital devices influence the micro-management of our life and provide opportunities to address individual, but also societal and/or community goals, produces a shift in the consolidated approaches to 'smart mobility' and 'smart transport'. These approaches usually refer to digital information as a tool to support integrated transport and flexible modal choice, as well as to manage traffic in real time via devoted control centres. A more radical approach, proposed in the spreading idea of 'mobility as a service' (Maas), relies instead on technologies and information for providing mobility in unprecedented forms. Within this framework, a platform intermediates between the traveller and the many transport providers: the traveller pays one commercial operator, who orchestrates different modal options into different trip alternatives. In this way, the traveller pays only once but has a full overview of the currently available modal options, according to their costs and travel times. The availability of information and devices that can arrange them is fundamental for allowing such innovative forms of mobility service provision.

However, information-based initiatives heavily rely on technologies, which on the contrary are not equally available to different strata of a population and are differently present according to the country taken into account. Issues of digital divide, due to the lack of economic resources or skills, reduce the effective availability of portable devices for significant shares of the population (Graham, 2011). Such subjects not only may be excluded from information-based initiatives that rely on technology, but may also be invisible when describing urban phenomena using big data: 
in fact, data do not represent those subjects who move without being tracked or who simply remain immobile due to insufficient economic resources or physical abilities to move (Sager, 2006).

\subsection{The shapers of information}

Manifold actors are currently developing information-based measures in the field of mobility, having a positive impact on individual mobility choices too. Several subjects - public administrations, corporations, communities - are in fact producers and owners of data that reflect individual choices and often contribute to the shaping of individual decisions. Their information is valuable in two senses:

- First, they collect real-time information that depict mobility practices not according to some estimations, as traditional transport planning models do, but rather considering their real development on a given territory. These subjects have thus available a significant source of information for a more precise and realistic portrait of urban mobility trends;

- Second, the impact of such information is crucial and yet not much investigated, suggesting peculiar experimental approaches. For example, this may be the case for real-time information and its impact on instinctive mobility choices (such as keep waiting for a specific service or go for another one, when knowing a delay; or using a service when its dynamic price changes).

Institutional actors, far from being the only player in this field, may sustain significant initiatives from a variety of subjects, in at least three ways.

First, public administrations should recognise which initiatives by corporations and communities can provide a significant improvement to urban mobility and support accordingly their development. Innovation in fact cannot rely exclusively on good ideas to better engage the marketplace, but rather as an occasion of social progress through the shared responsibilities with 
an institutional support (Feitselson \& Samuelson, 2004; Stigloe et al., 2014). In this sense, a priority requisite is the update of existing normative frameworks, whose relevance is twofold: first, their regulations often do not permit the development of technology-based innovative initiatives, due to dated norms; second, not even risks are adequately treated (for example, in terms of protecting users of the new services, or adapting privacy regulations to the new pervasive forms of data collection).

Second, the creative appropriation of digital devices into the micro-management of individuals mobility allows involving and engaging people in the generation, processing and analysis of data. A figure definable as the 'quantified traveller', who documents her mobility behaviours and reflects on it, emerge (Jariyasunant et al., 2015). Data can also contribute to enhance the delivery of mobility services, shaping their features according to the data collected and provided by travellers (Nunes, Galvão, \& Cunha, 2014), contributing to possible forms of 'coproduction' for mobility (Ciasullo, Palumbo, \& Troisi, 2017; Kudo, 2016; Vecchio, 2018).

Third, also a new attitude towards information is required: mobility-related data in fact are often owned by public administrations and companies that rarely share them publicly. In this sense, the definition of agreements for making data available is crucial for fostering information-based initiatives. While public bodies can push forward the provision of open data, management schemes for the information owned by other subjects (especially corporations) become necessary. By fostering the availability on information and defining suitable frameworks for their sharing, public subjects may act as enabler of information-based initiatives that face emerging mobility needs and opportunities. An example in this sense is Singapore Live!, a project that promotes "the development of an open platform for the collection, combination, and distribution of large numbers of a city's real-time data, allowing developer communities to join in creating applications that turn these data streams into meaningful and beneficial tools for people to make use of in their cities" 
(Kloeckl, Senn, \& Ratti, 2012, p. 90). In this sense, information-based policy becomes the occasion for capacity building, allowing citizens to put their abilities at work for addressing the wider needs of the communities they belong to.

\section{Conclusive remarks: Use the force, planner!}

To reinstate the relevance of information for urban mobility may seem redundant, given that we live in what has been defined long ago as 'the age of information' (Castells, 1996, 1997, 1998). However, it seems that the research fields exploring human behaviours and preferences still have not had significant interactions with the disciplines that study and face urban phenomena. As we have tried to show, information currently offers a much more complex portrait of ongoing phenomena, as well as inedited notions that are already influencing individual decisions and their collective reflections. Information is thus a powerful force behind urban phenomena that nonetheless still needs to be exploited, since policy approaches have only partially dealt with information and its impact on personal travel choices.

Information is a primary component in the definition of individual travel choices, even if its multiple features have a different influence according to the subjects taken into account. The recognition of the relevant role of information is part of an established literature on the differentiated individual abilities to move; nonetheless, a reference to behavioural theories may be useful to explain - at least in part - how spatial practices are formed and developed. The role of information is mainly investigated with surveys that directly asks to individuals what notions they value when planning their own mobility, but decisions are not the exclusive result of rational thinking processes. Behaviour-based experiments could be significant to observe hidden dynamics behind individual travel choices. The relevance of how information differently impacts individual 
decisions requires thus to move towards the (difficult) definition of protocols to observe it in action in the case of urban mobility.

In conclusion, information and its impact on individual mobility behaviour and preferences have a huge relevance for understanding and facing individual needs, as well as their impact on spatial phenomena. Such unexpressed potential highlights new learning needs, referred to the interpretation of data and, more importantly, of their varied influence on individual behaviours in urban settings. The emphasis on behavioural approaches has some potential risks, as highlighted by the fact that their operational reflections may lean towards 'forced choices' and assume "the idea that rational maximization is what people should do" (Berndt \& Boeckler, 2016, p. 23). Nonetheless, information allows to approach individuals more closely, contributing to overcome the limitations of traditional transport planning approaches based mainly on aggregations and estimations of individual travel choices. The huge influence of information and its promising contribution to urban planning and policy configure it as a powerful element for the understanding and the shaping of future cities, calling thus planners to learn how to make use of such force.

\section{Acknowledgments}

The paper is the expanded version of a work previously published in Italian, in Tricarico \& Vecchio (2018). The authors thank Stefano Testoni for his precious contribution to the ideas developed in the paper. Giovanni Vecchio also acknowledges the funding received from the European Union's Horizon 2020 research and innovation programme under grant agreement No 769608, as well as from the Centro de Desarrollo Urbano Sustentable (CEDEUS) (CONICYT/FONDAP 15110020). 


\section{Bibliographic references}

Aiken, M., Cairns B., Taylor M, e Moran R. (2011) «Community organisations controlling assets: a better understanding». Joseph Rowntree Foundation, 2011. https://www.jrf.org.uk/report/community-organisations-controlling-assets-betterunderstanding (Retrieved: 4 September 2018)

Anable, J. (2005). “Complacent Car Addicts”; or "Aspiring Environmentalists”? Identifying travel behaviour segments using attitude theory. Transport Policy, 12(1), 65-78. https://doi.org/10.1016/j.tranpol.2004.11.004

Banister, D., \& Bowling, A. (2004). Quality of life for the elderly: The transport dimension. Transport Policy, 11(2), 105-115. https://doi.org/10.1016/S0967-070X(03)00052-0

Bailey, N. (2012). The role, organisation and contribution of community enterprise to urban regeneration policy in the UK. Progress in Planning, 77(1), 1-35.

Barr, S., \& Prillwitz, J., (2014). A smarter choice? Exploring the behaviour change agenda for environmentally sustainable mobility. Environment and Planning C: Politics and Space, 32(1), 1-19. https://doi.org/10.1068/c1201

Berndt, C., \& Boeckler, M. (2016). Behave, global south! Economics, experiments, evidence. Geoforum, 70, 22-24. https://doi.org/10.1016/j.geoforum.2016.01.005

Boschma, R. (2005). Proximity and innovation: a critical assessment. Regional studies, 39(1), 6174.

Cairns, S., Sloman, L., Newson, C., Anable, J., Kirkbridge, A., \& Goodwin, P. (2008). Smarter choices: Assessing the potential to achieve traffic reductions using "soft measures." Transport Reviews, 28(5), 593-618. https://doi.org/10.1080/01441640801892504

Canzler, W., Kaufmann, V., \& Kesselring, S. (Eds.). (2008). Tracing mobilities. Farnham: 
Ashgate.

Cao, X., \& Mokhtarian, P. L. (2005). How do individuals adapt their personal travel? Objective and subjective influences on the consideration of travel-related strategies for San Francisco Bay Area commuters. Transport Policy, 12(4), 291-302. https://doi.org/10.1016/j.tranpol.2005.03.003

Castells, M. (1996). The Rise of the Network Society, The Information Age: Economy, Society and Culture Vol. I. Oxford: Blackwell.

Castells, M. (1997). The Power of Identity, The Information Age: Economy, Society and Culture Vol. II. Oxford: Blackwell.

Castells, M. (1998). End of Millennium, The Information Age: Economy, Society and Culture Vol. III. Oxford: Blackwell.

Ciasullo, M. V., Palumbo, R., \& Troisi, O. (2017). Reading Public Service Co-Production through the Lenses of Requisite Variety. International Journal of Business and Management, 12(2), 1. https://doi.org/10.5539/ijbm.v12n2p1

Cresswell, T. (2010). Towards a politics of mobility. Environment and Planning D: Society and Space, 28(1), 17-31. https://doi.org/10.1068/d11407

Elliott, A., \& Urry, J. (2010). Mobile Lives. London: Routledge.

Evans, D. S., \& Schmalensee, R. (2016). Matchmakers: The New Economics of Multisided Platforms. Cambridge: Harvard University Press.

Feitselson, E., \& Samuelson, I. (2004). The Political Economy of Transport Innovations. In M. Beuthe, V. Himanen, A. Reggiani, \& L. Zamparini (Eds.), Transport Developments and Innovations in an Evolving World. Berlin: Springer.

Flamm, M., \& Kaufmann, V. (2006). Operationalising the Concept of Motility: A Qualitative Study. Mobilities, 1(2), 167-189. https://doi.org/10.1080/17450100600726563 
Gebresselassie, M. \& Sanchez, T.W. (2018. "Smart” Tools for Socially Sustainable Transport: A Review of Mobility Apps. Urban Science, 2, 45.

Goodman, A., Jones, A., Roberts, H., Steinbach, R., \& Green, J. (2014). "We Can all just Get on a bus and Go": Rethinking Independent Mobility in the Context of the Universal Provision of Free Bus Travel to Young Londoners. Mobilities, 9(2), 275-293. https://doi.org/10.1136/jech-2012-201753.101

Goodchild, M. F. (2007). Citizens as sensors: the world of volunteered geography. GeoJournal, 69(4), 211-221. https://doi.org/10.1007/s10708-007-9111-y

Graham, M. (2011). Time machines and virtual portals: the spatialities of the digital divide. Progress in $\quad$ Development 211-27. https://doi.org/10.1177/146499341001100303

Hirson, R. (2015). Uber: The Big Data Company. Forbes. https://www.forbes.com/sites/ronhirson/2015/03/23/uber-the-big-datacompany/\#44561f4118c7 (Retrieved: 4 September 2018)

Jacquin, C. (2018). Network for transport open data. In State of the Map 2018. Milan, $28^{\text {th }}-30^{\text {th }}$ July.

Jariyasunant, J., Abou-Zeid, M., Carrel, A., Ekambaram, V., Gaker, D., Sengupta, R., \& Walker, J. L. (2015). Quantified Traveler: Travel Feedback Meets the Cloud to Change Behavior. Journal of Intelligent Transportation Systems, 19(2), 109-124. https://doi.org/10.1080/15472450.2013.856714

John, P., Smith, G., \& Stoker, G. (2009). Nudge nudge, think think: Two strategies for changing civic behaviour. The Political Quarterly, 80(3), 361-370.

Kahneman, D. (2011). Thinking, fast and slow. New York: Farrar, Straus and Giroux. Kaufmann, V. (2002). Re-Thinking Mobility. Farnham: Ashgate. 
Kazhamiakin, R., Marconi, A., Perillo, M., Pistore, M., Valetto, G., Piras, L., ... Perri, N. (2015).

Using Gamification to Incentivize Sustainable Urban Mobility. In 1st IEEE International Smart Cities Conference (pp. 1-6). https://doi.org/10.1109/ISC2.2015.7366196

Kellerman, A. (2012). Potential Mobilities. Mobilities, 7(1), 171-183. https://doi.org/10.1080/17450101.2012.631817

Kloeckl, K., Senn, O., \& Ratti, C. (2012). Enabling the Real-Time City: LIVE Singapore! Journal of Urban Technology, 19(10), 89-112. https://doi.org/10.1080/10630732.2012.698068

Knoben, J., Oerlemans, L. A. G., \& Rutten, R. P. J. H. (2008). The effects of spatial mobility on the performance of firms. Economic Geography, 84(2), 157-183.

Knockaert, J., Tsenga, Y. Y., Verhoef, E. T., \& Rouwendal, J. (2012). The Spitsmijdene xperiment: A reward to battle congestion. Transport Policy, 24, 260-272. https://doi.org/10.1016/j.tranpol.2012.07.007

Kronlid, D. (2008). Mobility as Capability. In Uteng, Tanu Priya \& T. Cresswell (Eds.), Gendered Mobilities. Aldershot: Ashgate.

Kudo, H. (2016). Co-design, Co-creation, and Co-production of Smart Mobility System. In P. L. Rau (Ed.), Cross-Cultural Design. CCD 2016 (Vol. 9741, pp. 551-562). Berlin: Springer. https://doi.org/10.1007/978-3-319-40093-8

Kwan, M.-P. (2016). Algorithmic Geographies: Big Data, Algorithmic Uncertainty, and the Production of Geographic Knowledge. Annals of the American Association of Geographers, 106(2), 274-282. https://doi.org/10.1080/00045608.2015.1117937

Larsen, J., Axhausen, K. W., \& Urry, J. (2006). Geographies of social networks: meetings, travel and communications. $\quad$ Mobilities, 261-283. https://doi.org/10.1080/17450100600726654

Macfarlane, G. S., Garrow, L. A., \& Mokhtarian, P. L. (2015). The influences of past and present 
residential locations on vehicle ownership decisions. Transportation Research Part A: Policy and Practice, 74, 186-200. https://doi.org/10.1016/j.tra.2015.01.005

Morozov, E. (2016). The state has lost control: tech firms now run western politics. The Guardian. https://www.theguardian.com/commentisfree/2016/mar/27/tech-firms-run-western-politicsevgeny-morozov (Retrieved: 4 September 2018)

Moroni, S., \& Tricarico, L. (2017). Distributed energy production in a polycentric scenario: policy reforms and community management. Journal of Environmental Planning and Management, $1-21$.

Nikitas, A., Kougias, I., Alyavina, E., \& Njoya Tchouamou, E. (2017). How Can Autonomous and Connected Vehicles, Electromobility, BRT, Hyperloop, Shared Use Mobility and MobilityAs-A-Service Shape Transport Futures for the Context of Smart Cities? Urban Science, 1, 36. https://doi.org/10.3390/urbansci1040036

Nordbakke, S. (2013). Capabilities for mobility among urban older women: barriers, strategies and options. Journal of Transport Geography, 26, 166-174. https://doi.org/10.1016/j.jtrangeo.2012.10.003

Nunes, A. A., Galvão, T., \& Cunha, J. F. e. (2014). Urban Public Transport Service Co-creation: Leveraging Passenger's Knowledge to Enhance Travel Experience. Procedia - Social and Behavioral Sciences, 111, 577-585. https://doi.org/10.1016/j.sbspro.2014.01.091

OECD (2015). Results of the OECD-CoR Consultation of Sub-national Governments. Infrastructure planning and investment across levels of government: current challenges and possible solutions. https://portal.cor.europa.eu/europe2020/pub/Documents/oecd-corjointreport.pdf (Retrieved: 4 September 2018)

Pasqui, G. (2015). Segnali di futuro? Spazi e pratiche del lavoro e della produzione a Milano. Imprese \& Città, 8: 51-55.

Priemus, H., Nijkamp, P., \& Banister, D. (2001). Mobility and spatial dynamics: an uneasy 
relationship. Journal of Transport Geography, 9(3), 167-171.

Rabari, C., \& Storper, M. (2015). The digital skin of cities: urban theory and research in the age of the sensored and metered city, ubiquitous computing and big data. Cambridge Journal of Regions, Economy and Society, 8(1), 27-42. https://doi.org/10.1093/cjres/rsu021

Ryan, J., Wretstrand, A., \& Schmidt, S. M. (2015). Exploring public transport as an element of older persons' mobility: A Capability Approach perspective. Journal of Transport Geography, 48, 105-114. https://doi.org/10.1016/j.jtrangeo.2015.08.016

Sager, T. (2006). Freedom as Mobility: Implications of the Distinction between Actual and Potential Travelling. Mobilities, 1(3), 465-488. https://doi.org/10.1080/17450100600902420

Schwanen, T. (2015). Beyond instrument: Smartphone app and sustainable mobility. European Journal of Transport and Infrastructure Research, 15(4), 675-690.

Sheller, M., \& Urry, J. (2003). Mobile Transformations of 'Public' and 'Private' Life. Theory, Culture \& Society, 20(3), 107-125. https://doi.org/10.1177/02632764030203007

Sheller, M., \& Urry, J. (2006). The new mobilities paradigm. Environment and Planning A, 38(2), 207-226. https://doi.org/10.1068/a37268

Sheller, M., \& Urry, J. (2016). Mobilizing the new mobilities paradigm. Applied Mobilities, 1(1), 10-25. https://doi.org/10.1080/23800127.2016.1151216

Simon, H. A. (1955). A behavioral model of rational choice. The quarterly journal of economics, 69(1), 99-118.

Smart, M. J., \& Klein, N. J. (2017). Remembrance of Cars and Buses Past: How Prior Life Experiences Influence Travel. Journal of Planning Education and Research. https://doi.org/10.1177/0739456X17695774

Song, C., Qu, Z., Blumm, N., \& Barabási, A.-L. (2010). Limits of predictability in human mobility. Science, 327(5968), 1018-21. https://doi.org/10.1126/science.1177170 
Stilgoe, J., Owen, R., \& Macnaghten, P. (2013). Developing a framework for responsible innovation. Research Policy, 42(9), 1568-1580.

Stjernborg, V., Wretstrand, A., \& Tesfahuney, M. (2014). Everyday Life Mobilities of Older Persons-A Case Study of Ageing in a Suburban Landscape in Sweden. Mobilities, 101(ahead-of-print), 1-19. https://doi.org/10.1080/17450101.2013.874836

Taylor, L. (2016). No place to hide? The ethics and analytics of tracking mobility using mobile phone data. Environment and Planning D: Society and Space, 34(2), 319-336. https://doi.org/10.1177/0263775815608851

te Brömmelstroet, M. (2014). Sometimes you want people to make the right choices for the right reasons: Potential perversity and jeopardy of behavioural change campaigns in the mobility domain. Journal of Transport Geography, 39, 141-144. https://doi.org/10.1016/j.jtrangeo.2014.07.001

Thaler, R. H., \& Sunstein, C. (2008). Nudge: Improving Decisions about Health, Wealth, and Happiness. New Haven: Yale University Press.

Tracey, P., Phillips, N., \& Haugh, H. (2005). Beyond philanthropy: Community enterprise as a basis for corporate citizenship. Journal of business ethics, 58(4), 327-344.

Tricarico, L., Vecchio, G., \& Testoni, S. (2016). Comunità di pratiche della mobilità urbana: innovazione, condivisione e behavioural economics. Working Papers. Rivista Online Di Urban@it,1.

Tricarico, L. (2016). Imprese di comunità come fattore territoriale: riflessioni a partire dal contesto italiano. CRIOS, 11, 35-50.

Tricarico, L. (2017). Community action: value or instrument? an ethics and planning critical review. Journal of Architecture and Town Planning, 41(3), 221-233.

Tricarico, L., Vecchio, G. (Eds.), Mobilità è sviluppo. Strumenti e competenze per il futuro della 
mobilità, Fondazione Giangiacomo Feltrinelli, Milano.

Turkle, S. (2011). Alone Together. New York: Basic Books.

Uber. (2017). Uber Movement: Let's find smarter ways forward. https://movement.uber.com/cities (Retrieved: 4 September 2018)

Urry, J. (2007). Mobilities. Cambridge: Polity Press.

van Ham, M., Reuschke, D., Kleinhans, R., Mason, C. and Syrett, S. (Eds.) (2017), Entrepreneurial Neighbourhoods: Towards an Understanding of the Economies of Neighbourhoods and Communities. Celtenham: Elgar.

van Wee, B., Geurs, K., \& Chorus, C. (2013). Information, communication, travel behavior and accessibility. Journal of Transport and Land Use, 6(3), 1-16.

Vecchio, G. (2016). Complicare il movimento. Nuove forme di organizzazione per i servizi della mobilità urbana. In M. Talia (Ed.), Un nuovo ciclo della pianificazione urbanistica tra tattica e strategia / A new cycle of Urban Planning between Tactic and Strategy. Rome - Milan: Planum Publisher.

Vecchio, G. (2018). Producing Opportunities Together: Sharing-Based Policy Approaches for Marginal Mobilities in Bogotá. Urban Science, 2(3), 54.

(C) 2018. This manuscript version is made available under the CC-BY-NC-ND 4.0 license http://creativecommons.org/licenses/by-nc-nd/4.0/ 